\title{
Sensitivity Analysis of PBL Physics Schemes of WRF-ARW Model in Simulating the Tropical Cyclone 'TITLI' (2018) Over the Bay of Bengal
}

\author{
Saifullah, M. I. Ali* \\ Department of Physics, Khulna University of Engineering \& Technology, Khulna, Bangladesh
}

Received 10 April 2021, accepted in final revised form 21 June 2021

\begin{abstract}
Tropical Cyclone (TC) is the most destructive weather phenomenon in the Indian subcontinent. To mitigate the destruction due to TC better prediction is needed. So, the study of sensitivity of different physical schemes in WRF-ARW model with intensification and track of TC is important. In this study, sensitivity of Yonsei University (YSU), Asymmetric Convective Model version 2 (ACM2), Bougeault-Lacarrere (Boulac), Medium-Range Forecast (MRF), Mellor-Yamada Nakanishi and Niino Level 2.5 (MYNN2.5) and Level 3 (MYNN3) Planetary Boundary Layer (PBL) schemes are used to simulate the TC 'Titli' which made land fall near Palasa in North Andrha Pradesh and South Odhisha coasts at 0000 UTC of $11^{\text {th }}$ October. National center for environmental prediction Global Final Reanalysis (FNL) data have been used as an initial and lateral boundary conditions. Variation of heat flux, latent heat flux and moisture flux with time for these schemes are shown which are responsible to intensify the TC. Model simulated intensity i.e., minimum central pressure, maximum sustained wind speed at the surface $(10 \mathrm{~m})$ and track are compared with the India Meteorological Department (IMD) estimated value. It can be specified that the Boulac, MYNN2.5 and MYNN3 schemes simulate the better intensity and track of TC 'Titli'.
\end{abstract}

Keywords: Tropical cyclone; WRF-ARW; PBL schemes; FNL data; IMD.

(C) 2021 JSR Publications. ISSN: 2070-0237 (Print); 2070-0245 (Online). All rights reserved. doi: http://dx.doi.org/10.3329/jsr.v13i3.52935

J. Sci. Res. 13 (3), 851-867 (2021)

\section{Introduction}

Tropical cyclones (TCs) are known as the foremost familiar and irresistible natural catastrophes in the Earth's atmospheric system [1]. Every year, almost 70-80 TC events arise over the whole world. The maximum sustained surface wind speeds of these TCs are more than $17 \mathrm{~m} / \mathrm{s}$, and almost $60 \%$ reach the very severe cyclonic storm systems with wind speeds of more than $33 \mathrm{~m} / \mathrm{s}$ [2]. Bay of Bengal $(\mathrm{BoB})$ is the peak-prone area for the growth of some powerful and destructive TCs. Almost seven percent of yearly total storms are occurred in this BoB area [3]. The Indian subcontinent, mostly Bangladesh and India, are treated as one of the most cyclone-affected areas globally due to their unique geo-climatic environments and densely populated coastal region. Generally, these TCs

\footnotetext{
*Corresponding author: idrisali19929@gmail.com
} 
occur during March-May called pre-monsoon and October-December called postmonsoon seasons. Mainly the post-monsoon season observes the highest number of cyclone formations with severe intensity over BoB [4,5]. Almost 3-4 cyclonic storms form in the BoB over the whole year [6].

TCs are intense low-pressure systems. This system originates over the warm tropical ocean [5]. The cyclones generally form in the BoB region; the tracks, as many of them move north and re-curve to India's northeast direction [7]. Low-level cyclonic vorticity, a critical value of earth vorticity, lower vertical wind shear, potentially unstable atmosphere, higher sea surface temperature, and higher mid-tropospheric humidity are the main favorable situations for the development of TCs [3,5]. Earth vorticity is a consequence of earth rotation and is passed through friction to the atmosphere. The changes of vorticity are used for the calculation of divergence. Higher vorticity indicates the ageostrophic flow and upper-level divergence. When intense winds, torrential rains, and large storm surges are joined together with these TCs, they show their most catastrophic nature [8].

The prediction of the development of track and intensity of TCs can remarkably helpful for reducing the loss of life and assets. Many researchers in previous years have done their research work about the simulation of TCs with a numerical forecasting model. This numerical model consists of a various number of physics components, i.e., Micro Physics (MP) schemes, Planetary Boundary Layer (PBL) schemes, Cumulus Parameterization (CP) schemes, Surface Layer physics, and so on. These components play a significant role in the correct prediction of TC. Many researchers [9-13] have studied the sensitivity of different physical parameterization schemes and found significant influences of these schemes on the simulation of TCs.

Srinivas et al. and Singh et al. [14,15] have found the best performance of KF scheme due to downdrafts, updrafts, and shallow convection. Osuri et al. [16] have found a good forecast of intensity, track, and rainfall associated with TC by the YSU-KF (YKF) combination. This combination has formed strong horizontal wind speed, resilient convergence with strong updrafts inside the warmer cyclone core. Kanase and Salvekar [17] studied the parameterization sensitivity of cyclone Laila and found a good forecast of track and intensity for the YSU scheme. Singh and Bhaskaran [18] found a result that proves that the YSU PBL and the old simplified Arakawa-Schubert CP scheme simulated better performance in the case of both track and intensity. Kanada et al. [19] have examined the sensitivity of various PBL schemes, i.e., level 2.5 and level 3 MellorYamada-Nakanishi-Niino closure schemes, a nonlocal scheme, and the DeardorffBlackadar scheme, and found that they play a vital role to determine the maximum intensity of TC. Among them, level 2.5 and level 3 Mellor-Yamada-Nakanishi-Niino closure schemes were found to be better. Rajeswari et al. [20] have examined the impact of various PBL schemes, i.e., YSU, MYJ, QNSE, MYNN, and Boulac, on TC. They observed that PBL physics generally influenced the intensity while making minor deviations in track forecast and found a better agreement with the observation for the YSU PBL scheme. 
In our present study, 48, 72, and $96 \mathrm{~h}$ of simulations were organized by using six various PBL schemes, i.e., Yonsei University (YSU) Scheme [21], Asymmetric Convective Model version 2 (ACM2) Scheme [22], Bougeault-Lacarrere (Boulac) Scheme [23], Medium-Range Forecast (MRF) Scheme [24], Mellor-Yamada Nakanishi and Niino Level 2.5 (MYNN2.5) Scheme and Mellor-Yamada Nakanishi and Niino Level 3 (MYNN3) Scheme [25-27] with WRF Double Moment 6-class (WDM6) [28] MP scheme and Kain-Fritsch (KF) [29-31] CP scheme. The KF scheme accounted for the mesoscale procedures that make possible improvement of the convective movement.

For more precious simulation of the deeper mixing within an unstable PBL the MRF are very suitable. In strong-wind regions at night, too deep of mixing results in over erosion of convective initiation. The accuracy of YSU is more than the MRF in the case of the simulation of deeper vertical mixing in buoyancy-driven PBLs through shallower mixing in strong-wind systems. It has still been found to over-deepen the PBL for springtime deep convective environments, resulting in too much dry air near the surface. MYNN2.5 contains a lesser amount of computational expense than MYNN3. MYNN3 more correctly depicts deeper mixed layers with respect to the Mellor-Yamada PBL scheme. MYNN2.5 enhances the PBL schemes for springtime PBLs which boosts the deep convection. Better representation of the PBL is observed for the Boulac scheme in the systems of greater static stability in comparison with the nonlocal schemes. The local origination of the MYNN2.5, MYNN3, and Boulac might not wholly account for deeper vertical mixing connected with greater eddies and associated counter gradient flux correction terms. The potential temperature and velocity profile are portrayed with the larger precision through the PBL by ACM2 scheme. Evening soundings are supporting deep convection with too deep PBLs characterized by the ACM2 scheme.

The primary objective of our current study is to examine the influence of PBL schemes in WRF-ARW model on the simulation of TC 'Titli' or to investigate the intensity, track pattern, and energy of TC 'Titli', which formed over BoB during 08-13 October 2018.

\section{A Brief Description of a Very Severe Cyclonic Storm (VSCS) 'TITLI'}

The "TITLI" was a very severe cyclonic storm (VSCS) that happened over the BoB during 08-13 October 2018. In the morning of $7^{\text {th }}$ October, a low-pressure system is formed over the southeast BoB and the adjacent north Andaman Sea. This low-pressure system turns into the well-marked low pressure in the afternoon of $7^{\text {th }}$ October. Then it concentrated into Depression (D) over BoB in the morning of $8^{\text {th }}$ October. After midnight it tends to a Deep depression (DD). Around the morning of $9^{\text {th }}$ October, it turned into Cyclonic Storm (CS) "Titli". Therefore, around $10^{\text {th }}$ October, it deepened into a severe cyclonic storm (SCS). On $11^{\text {th }}$ October, it crossed the north Andhra Pradesh coasts and made landfall near Palasa as VSCS. After that, it is weakened into DD and D at midnight $11^{\text {th }}$ and $12^{\text {th }}$ October, respectively [32]. 


\section{Data Used}

The National Center for Environment Prediction (NCEP) Final Analysis (FNL) data $\left(1^{\circ} \times\right.$ $1^{\circ}$ ) spatial resolution) is used as an initial and lateral boundary condition to the model, which is updated at every six hour interval. The simulated Lowest Estimated Central Pressure (LECP), Maximum Sustained Wind Speed (MSWS) at the surface, and the tracks are compared with the estimated value of the India Meteorological Department (IMD).

\section{WRF Model Dynamics and Domain Configuration}

The weather research and forecasting (WRF) model are a well-known numerical weather prediction (NWP) model for the university/research and operational communities. Here WRF (ARW) version 3.8.1 was used in our present study. It is very suitable for scales ranging from meters to thousands of kilometers in a wide range of applications. Various multi-agencies and many university scientists of the world collaboratively trying to improve the WRF model for making a next-generation mesoscale forecast model and data assimilation system. The overall WRF code system is maintained by the Mesoscale and Microscale Meteorology Division of the National Center for Atmospheric Research (NCAR). Various prognostic variables having conservation properties and fully compressible non-hydrostatic Euler equations are included in this WRF model. Also, the curvature, moisture, and Coriolis terms are included in the equation sets of WRF model. Also, the lateral boundary conditions, diffusion, and nesting are additionally incorporated into WRF model $[33,34]$.

Table 1. Details of WRF model dynamics and domain.

\begin{tabular}{|c|c|c|c|}
\hline Dynamics & & Domain & \\
\hline WRF core & ARW & No. of domains & 1 \\
\hline Equation & Non-hydrostatic & Central of the domain & $\begin{array}{l}\text { lat- } 17.5^{\circ} \mathrm{N} \quad \& \quad \text { lon- } \\
87.5^{\circ} \mathrm{E}\end{array}$ \\
\hline Vertical co-ordinate & $\begin{array}{l}\text { Terrain-following } \\
\text { hydrostatic-pressure }\end{array}$ & $\begin{array}{l}\text { Horizontal grid } \\
\text { distance }\end{array}$ & $9 \mathrm{~km}$ \\
\hline $\begin{array}{l}\text { Time integration } \\
\text { scheme }\end{array}$ & $\begin{array}{l}3^{\text {rd }} \text { order Runge-Kutta } \\
\text { scheme }\end{array}$ & No. of grid points & EW-100 \& NS-100 \\
\hline Horizontal grid type & Arakawa-C grid & No. of vertical layers & 30 \\
\hline Map projection & Mercator & Time steps & $45 \mathrm{~s}$ \\
\hline
\end{tabular}

In this current study, the WRF model was run for $96 \mathrm{~h}$ (0000 UTC of 8-12 October 2018), $72 \mathrm{~h}$ (0000 UTC 9-12 October 2018), and $48 \mathrm{~h}$ (0000 UTC of 10-12 October 2018) to simulate the track, intensity and different meteorological parameters are related to the VSCS Titli. The model was run with a single domain. The horizontal resolution of the model domain is $9 \mathrm{~km}$. 30 vertical terrains following eta levels are used for the simulation of VSCS Titli. The center of the domain is $17.5^{\circ} \mathrm{N} / 87.5^{\circ} \mathrm{E}$. In east-west and north-south direction, the number of grid points is 100 . To maintain the computational stability, the time step of integration was set at $45 \mathrm{sec}$. The horizontal grid is the Arakawa C-grid 
staggering. The third-order Runge-Kutta (RK3) scheme was used for the time-split integration for maintaining numerical stability. The Monin-Obukhov similarity theory scheme was included as a surface layer. The Dudhia scheme [35] was used for short wave radiation (SWR), and Rapid Radiative Transfer Model (RRTM) [36] was used for longwave radiation (LWR). At a glance, the complete dynamics, domain, and physics schemes of the WRF model simulation are given in Table 1 and Table 2.

Table 2. List of WRF model physics used in this study.

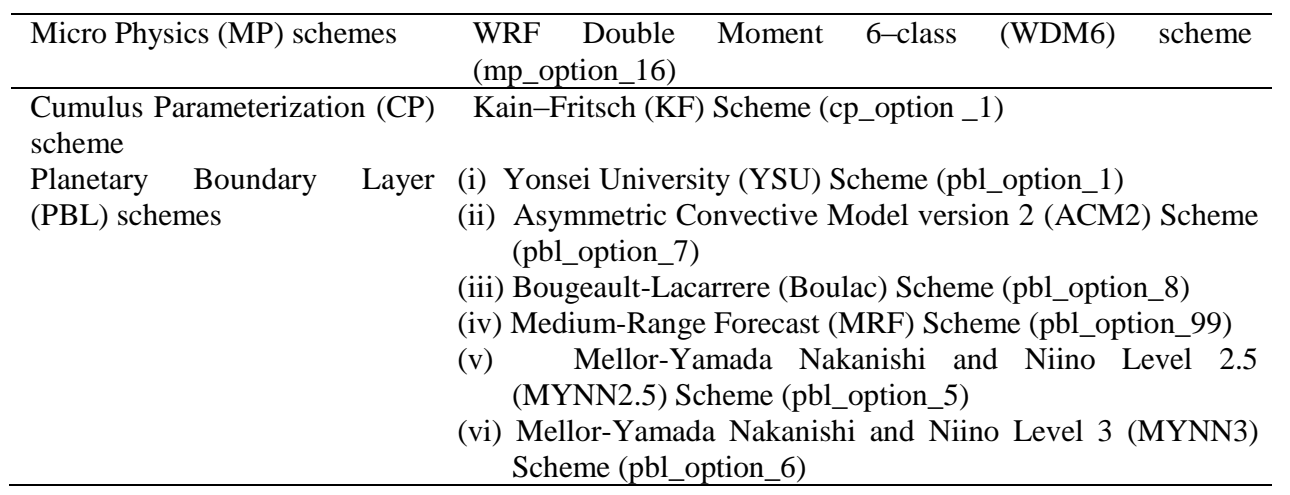

\section{Verification of the Model Predictions/Performance Evaluation for WRF Model}

The model predictions during the period of 8-12 October 2018 have been verified using simple model statistics, i.e., Root Mean Square Error (RMSE) and the Correlation Coefficient (CC) between observed and simulated data. The best scheme has been investigated according to the movement of the simulated track, various track errors, and the analysis of the intensity of TC Titli. Again, the least RMSE and the CC near 1 are very good indicators for a good prediction. The RMSE and CC are mathematically expressed as follows:

$$
\begin{aligned}
& R M S E=\sqrt{\frac{\sum_{i=1}^{N}\left(X_{\bmod e l, i}-X_{o b s, i}\right)^{2}}{N}} \\
& C C=\frac{\sum_{i=1}^{N}\left(\left(X_{\bmod e l, i}-\overline{X_{\bmod e l}}\right)\left(X_{o b s, i}-\overline{X_{o b s}}\right)\right)}{\sum_{i=1}^{N}\left(X_{\bmod e l, i}-\overline{X_{\bmod e l}}\right)^{2} \sum_{i=1}^{N}\left(X_{o b s, i}-\overline{X_{o b s}}\right)^{2}}
\end{aligned}
$$

Where $\mathrm{N}$ is the total number of simulated outputs, $X_{\text {model }, i}$ is the model simulated values, $X_{o b s, i}$ is the observed values. $\overline{X_{\text {model }}}$ and $\overline{X_{o b s}}$ are the average of the model-simulated and observed values, respectively [37-39]. 


\section{Results and Discussion}

\subsection{Track of VSCS 'TITLI'}
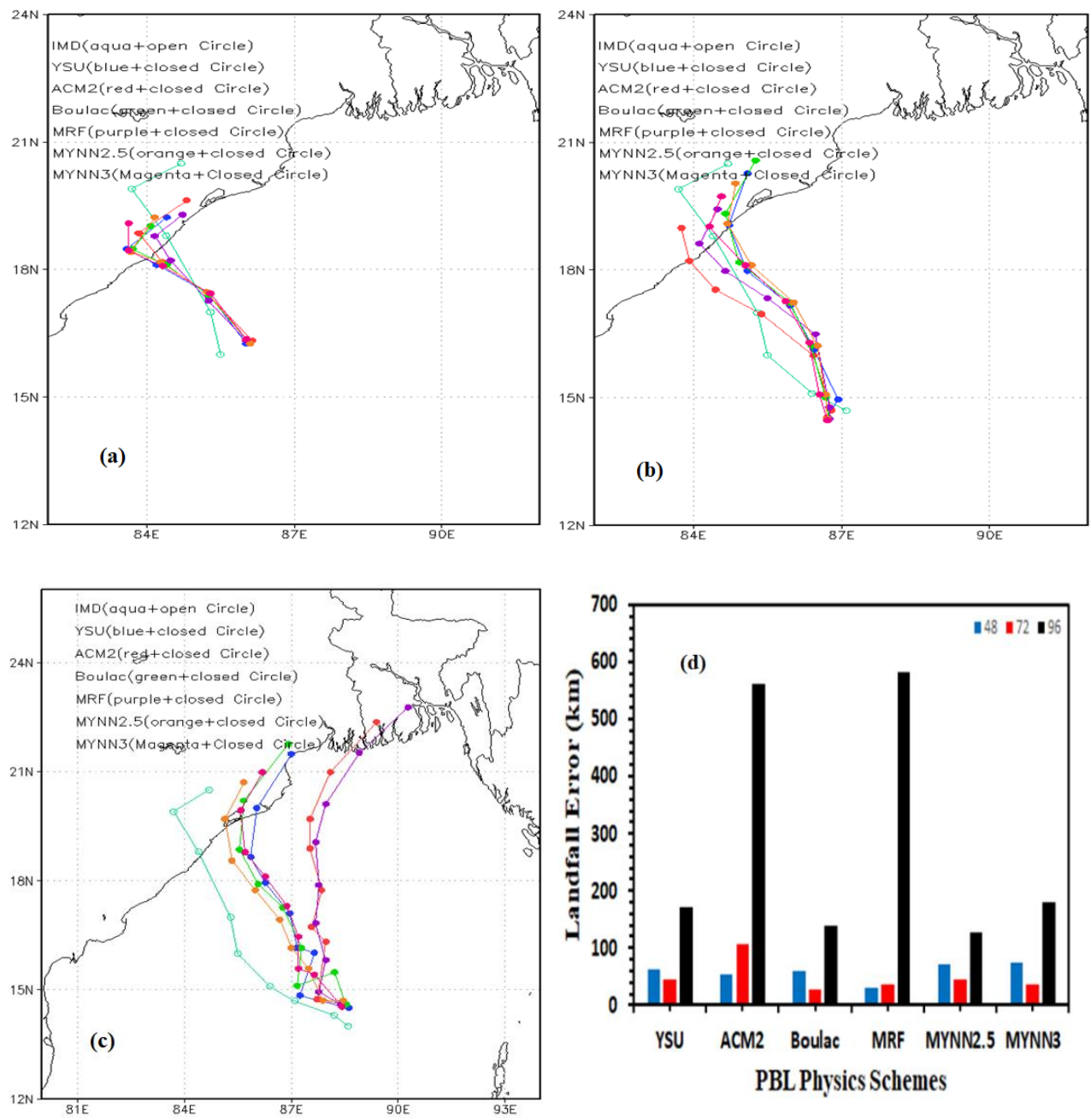

Fig. 1. The time evolution of observed and IMD estimated tracks of VSCS Titli for (a) $48 \mathrm{~h}$ during 0000 UTC of 10-12 October 2018, (b) $72 \mathrm{~h}$ during 0000 UTC of 09-12 October 2018, and (c) $96 \mathrm{~h}$ during 0000 UTC of 08-12 October 2018 with six different PBL schemes. (d) Average landfall error $(\mathrm{km})$ with six different PBL schemes.

Effect of various PBL parameterization schemes on the track of TC 'Titli' for 48, 72, and $96 \mathrm{~h}\left(0000 \mathrm{UTC}\right.$ of $10^{\text {th }}, 9^{\text {th }}$ and $8^{\text {th }}$ October 2018) simulation are shown in Fig. 1(a-c), respectively. All track data that is found from the model is plotted along with IMD estimated track data. All tracks show northwesterly movement until the landfall storm, and after that, all tracks deviate slightly to the right. 
From Fig. 1(c), at $96 \mathrm{~h}\left(0000\right.$ UTC of $8^{\text {th }}$ October) simulation, all tracks have deviated from IMD estimated track westerly. MRF and ACM2 schemes simulated track have shown huge deviation from the actual observed track. MYNN2.5 scheme simulated track for $96 \mathrm{~h}$ simulation is very close to the IMD observed track compared to other PBL schemes simulated track. On the other hand, ACM2 and MYNN2.5 simulated track are slightly close to IMD observed track for 72 and $48 \mathrm{~h}$ (0000 UTC of 9th and 10th October) simulation is shown in Fig. 1(a-b).

Table 3. Observed and model-simulated landfall time, landfall position, landfall position error, and time error of VSCS 'Titli' for different PBL schemes ( $\mathrm{D}^{*}=$ Delayed landfall) for $48 \mathrm{~h}$ simulation.

\begin{tabular}{lllll}
\hline PBL schemes & Landfall time & $\begin{array}{l}\text { Position } \\
(1 \text { at. }\end{array}$ & $\begin{array}{l}\text { Landlon. } .^{\circ} \text { E) } \\
\text { error }(\mathrm{km})\end{array}$ & $\begin{array}{l}\text { Time error } \\
(\mathrm{h})\end{array}$ \\
\hline YSU & 0600 UTC of $11^{\text {th }}$ October & $18.58 / 83.88$ & 62.73 & $06 \mathrm{D}^{*}$ \\
ACM2 & 0600 UTC of $11^{\text {th }}$ October & $18.58 / 83.96$ & 54.65 & $06 \mathrm{D}^{*}$ \\
Boulac & 0600 UTC of $11^{\text {th }}$ October & $18.41 / 84.04$ & 58.97 & $06 \mathrm{D}^{*}$ \\
MRF & 0600 UTC of $11^{\text {th }}$ October & $18.58 / 84.24$ & 30.22 & $06 \mathrm{D}^{*}$ \\
MYNN2.5 & 0600 UTC of $11^{\text {th }}$ October & $18.48 / 83.84$ & 71.66 & $06 \mathrm{D}^{*}$ \\
MYNN3 & 0600 UTC of $11^{\text {th }}$ October & $18.48 / 83.80$ & 75.55 & $06 \mathrm{D}^{*}$ \\
IMD & 2300 UTC of $10^{\text {th }}-0000$ & $18.8 / 84.5$ & & \\
& UTC of $11^{\text {th }}$ October & & & \\
\hline
\end{tabular}

Table 4. Observed and model-simulated landfall time, landfall position, landfall position error, and time error of VSCS 'Titli' for different PBL schemes ( $\mathrm{D}^{*}=$ Delayed of landfall) for $72 \mathrm{~h}$ simulation.

\begin{tabular}{lllll}
\hline $\begin{array}{l}\text { PBL } \\
\text { schemes }\end{array}$ & Landfall time & $\begin{array}{l}\text { Position } \\
(\text { lat. }\end{array}$ N/lon. $\left.{ }^{\circ} \mathrm{E}\right)$ & $\begin{array}{l}\text { Landfall position } \\
\text { error }(\mathrm{km})\end{array}$ & $\begin{array}{l}\text { Time } \\
\text { error }(\mathrm{h})\end{array}$ \\
\hline YSU & 1200 UTC of $11^{\text {th }}$ October & $19.05 / 84.71$ & 44.24 & $12 \mathrm{D}^{*}$ \\
ACM2 & 1200 UTC of $11^{\text {th }}$ October & $17.87 / 84.12$ & 107.91 & $12 \mathrm{D}^{*}$ \\
Boulac & 0600 UTC of $11^{\text {th }}$ October & $18.82 / 84.65$ & 35.90 & $06 \mathrm{D}^{*}$ \\
MRF & 0600 UTC of $11^{\text {th }}$ October & $18.5 / 84.28$ & 27.86 & $06 \mathrm{D}^{*}$ \\
MYNN2.5 & 0600 UTC of $11^{\text {th }}$ October & $19.09 / 84.69$ & 45.56 & $06 \mathrm{D}^{*}$ \\
MYNN3 & 0600 UTC of $11^{\text {th }}$ October & $18.58 / 84.65$ & 37.00 & $06 \mathrm{D}^{*}$ \\
IMD & 2300 UTC of $10^{\text {th }}-0000$ & $18.8 / 84.5$ & & \\
& UTC of $11^{\text {th }}$ October & & & \\
\hline
\end{tabular}

Table 5. Observed and model-simulated landfall time, landfall position, landfall position error, and time error of VSCS 'Titli' for different PBL schemes ( ${ }^{*}=$ Delayed landfall) for $96 \mathrm{~h}$ simulation.

\begin{tabular}{|c|c|c|c|c|}
\hline $\begin{array}{l}\text { PBL } \\
\text { schemes }\end{array}$ & Landfall time & $\begin{array}{l}\text { Position } \\
\left.\text { (lat. }{ }^{\circ} \text { N/lon. }{ }^{\circ} \mathrm{E}\right)\end{array}$ & $\begin{array}{l}\text { Landfall position } \\
\text { error }(\mathrm{km})\end{array}$ & $\begin{array}{l}\text { Time error } \\
\text { (h) }\end{array}$ \\
\hline YSU & 0600 UTC of $11^{\text {th }}$ October & $22.27 / 91.83$ & 171.11 & $06 \mathrm{D}^{*}$ \\
\hline ACM2 & 1200 UTC of $11^{\text {th }}$ October & $22.55 / 91.50$ & 562.28 & $12 \mathrm{D}^{*}$ \\
\hline Boulac & 0300 UTC of $11^{\text {th }}$ October & $21.84 / 91.89$ & 138.74 & $03 \mathrm{D}^{*}$ \\
\hline MRF & 0600 UTC of $11^{\text {th }}$ October & $21.30 / 92.00$ & 583.66 & $06 \mathrm{D}^{*}$ \\
\hline MYNN2.5 & 0600 UTC of $11^{\text {th }}$ October & $22.45 / 91.67$ & 127.89 & $06 \mathrm{D}^{*}$ \\
\hline MYNN3 & 0600 UTC of $11^{\text {th }}$ October & $19.93 / 85.58$ & 181.53 & $06 \mathrm{D}^{*}$ \\
\hline IMD & $\begin{array}{l}2300 \text { UTC of } 10^{\text {th }}-0000 \\
\text { UTC of } 11^{\text {th }} \text { October }\end{array}$ & $18.8 / 84.5$ & & \\
\hline
\end{tabular}


The average landfall errors are presented in Fig. 1(d), measured by comparing simulated landfall with IMD observed landfall $\left(18.8^{\circ} \mathrm{N}\right.$ latitude and $84.5^{\circ} \mathrm{E}$ longitude). Tables 3-5 show the observed and model-simulated landfall time, landfall position, landfall position error, and landfall time error for 48, 72, and $96 \mathrm{~h}$ simulation.

\subsection{Track error analysis}

The time variation of track error $(\mathrm{km})$ has been presented in Fig. 2 (a-c) for different PBL schemes used in this study by comparing it with IMD observation data. From these figures, it is clear that track error is increased rapidly after the landfall (2300 UTC of $10^{\text {th }}$ October to 0000 UTC of $11^{\text {th }}$ October) due to the land friction, vegetation, etc. On the other hand, before the landfall of the system, track error seems slight variation with time. In $96 \mathrm{~h}$ simulation (0000 UTC of $8^{\text {th }}$ October), the variation of track error with time is maximum for MRF scheme and minimum for MYNN2.5 scheme. The following figures ACM2 schemes have shown almost maximum track error for 96 and 72 simulations, but it has shown the minimum for $48 \mathrm{~h}$ simulation.
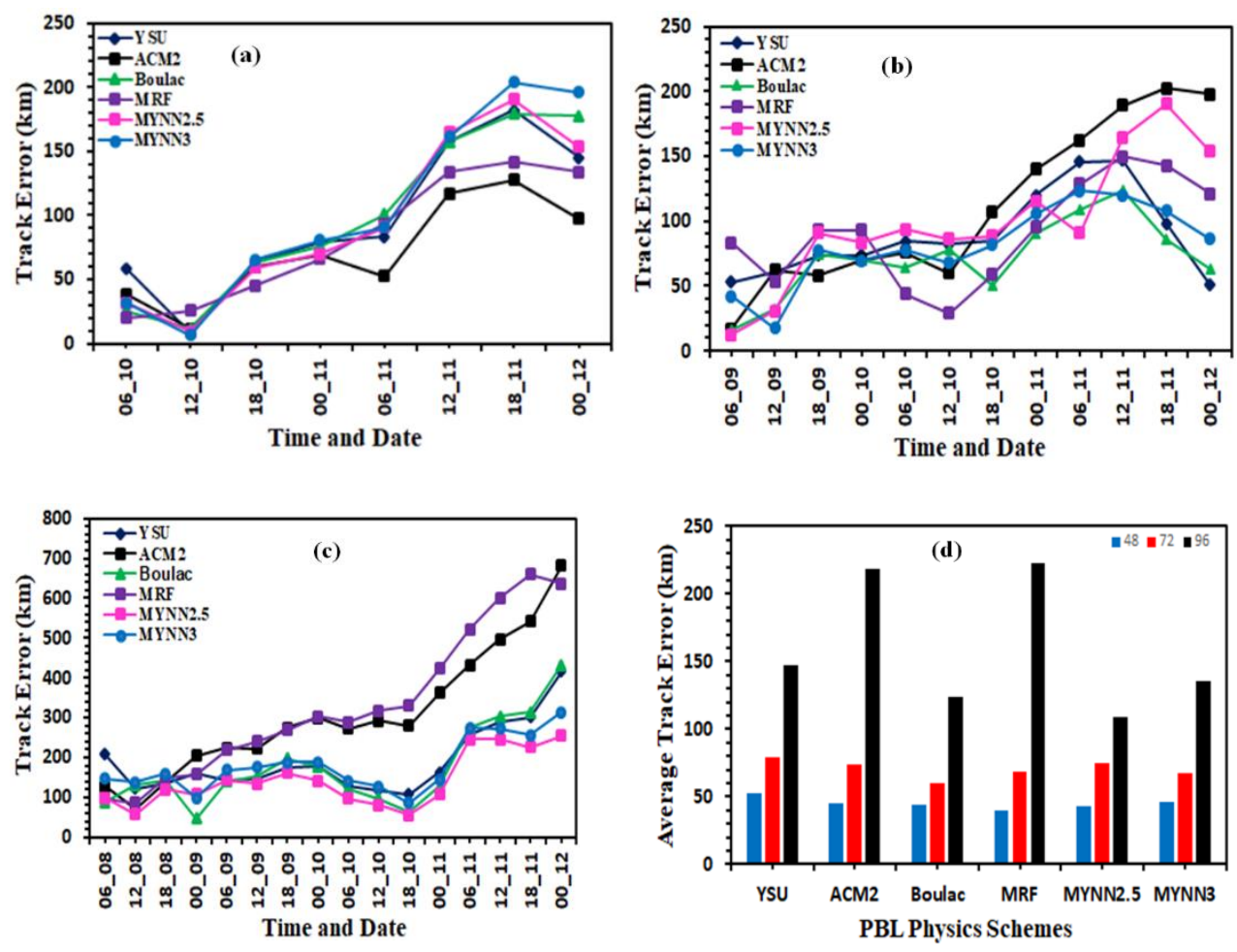

Fig. 2. Variation of track error in terms of km with time (a) 48, (b) 72, (c) $96 \mathrm{~h}$ simulation, and (d) average track error. 
Average track errors have been calculated from initial time (0000 UTC of $8^{\text {th }}, 9^{\text {th }}$ and $10^{\text {th }}$ October 2018) to landfall time (0000 UTC of $11^{\text {th }}$ October 2018), and the results are presented in the histogram diagram (Fig. 2(d)). Maximum average track error is found 222 $\mathrm{km}$ for MRF scheme and minimum is found $108 \mathrm{~km}$ for MYNN2.5 scheme at $96 \mathrm{~h}$ simulation. At $72 \mathrm{~h}$ simulation, YSU scheme has shown maximum average track error and Boulac scheme shown minimum average track error. Fig. 2(d) shows that Boulac and MYNN2.5 schemes show overall minimum average track error.

\subsection{Minimum central pressure (MCP)}

The intensity of any TCs is measured in terms of MCP and maximum sustained wind speed (MSWS) that's why a variation of MCP with time is very important. The propagation of simulated MCP by using YSU, Boulac, ACM2, MRF, MYNN2.5, and MYNN3 PBL schemes in WRF-ARW model is presented with IMD Observed LECP in Fig. 3(a-c) for (a) $48 \mathrm{~h}$ during 0000 UTC of $10^{\text {th }}-12^{\text {th }}$ October 2018, (b) $72 \mathrm{~h}$ during 0000 UTC of $09^{\text {th }}-12^{\text {th }}$ October 2018 and (c) 96 h during 0000 UTC of $08^{\text {th }}-12^{\text {th }}$ October 2018. Before the landfall (2300 UTC of $10^{\text {th }}-0000$ UTC of $11^{\text {th }}$ October) of the system, at $48 \mathrm{~h}$ simulation (0000 UTC of $10^{\text {th }}-12^{\text {th }}$ October) Boulac, MYNN2.5, and MYNN 3 schemes simulated central pressure are very close to IMD estimated central pressure. After the landfall, all PBL schemes simulated central pressure very lower than IMD estimated pressure. The lowest pressure was simulated by ACM2 schemes at 0000 UTC of $11^{\text {th }}$ October, which means that maximum intensity occurred at that time.

On the other hand, for 72 and $96 \mathrm{~h}$ simulations, MRF schemes simulated central pressure is slightly close to IMD estimated central pressure (Fig. 3(b-c)). Other schemes simulated central pressure is lower than IMD estimated and the lowest pressure simulated by YSU schemes and ACM2 schemes for $72 \mathrm{~h}$ and $96 \mathrm{~h}$ simulations, respectively, which means that YSU and ACM2 schemes overestimated the cyclone intensity. All these schemes predicted TC 'Titli' maximum intensity approximately 0600 UTC of $11^{\text {th }}$ October but from IMD estimated value found at 0000 UTC of $11^{\text {th }}$ October. All the simulated MCP is lower than IMD observed MCP except MRF schemes. However, the PBL schemes are very sensitive to the simulation of TCs over BoB. The RMSE and CC of minimum central pressure are presented in Table 6 . When the model continuously shows a low RMSE value, it indicates the highest efficiency of the model. The RMSE of MCP is very low; it indicates that the model deviated less from the IMD observed value. The $\mathrm{CC}$ value also shows the good prediction of TC Titli simulation for 48 and $96 \mathrm{~h}$. 

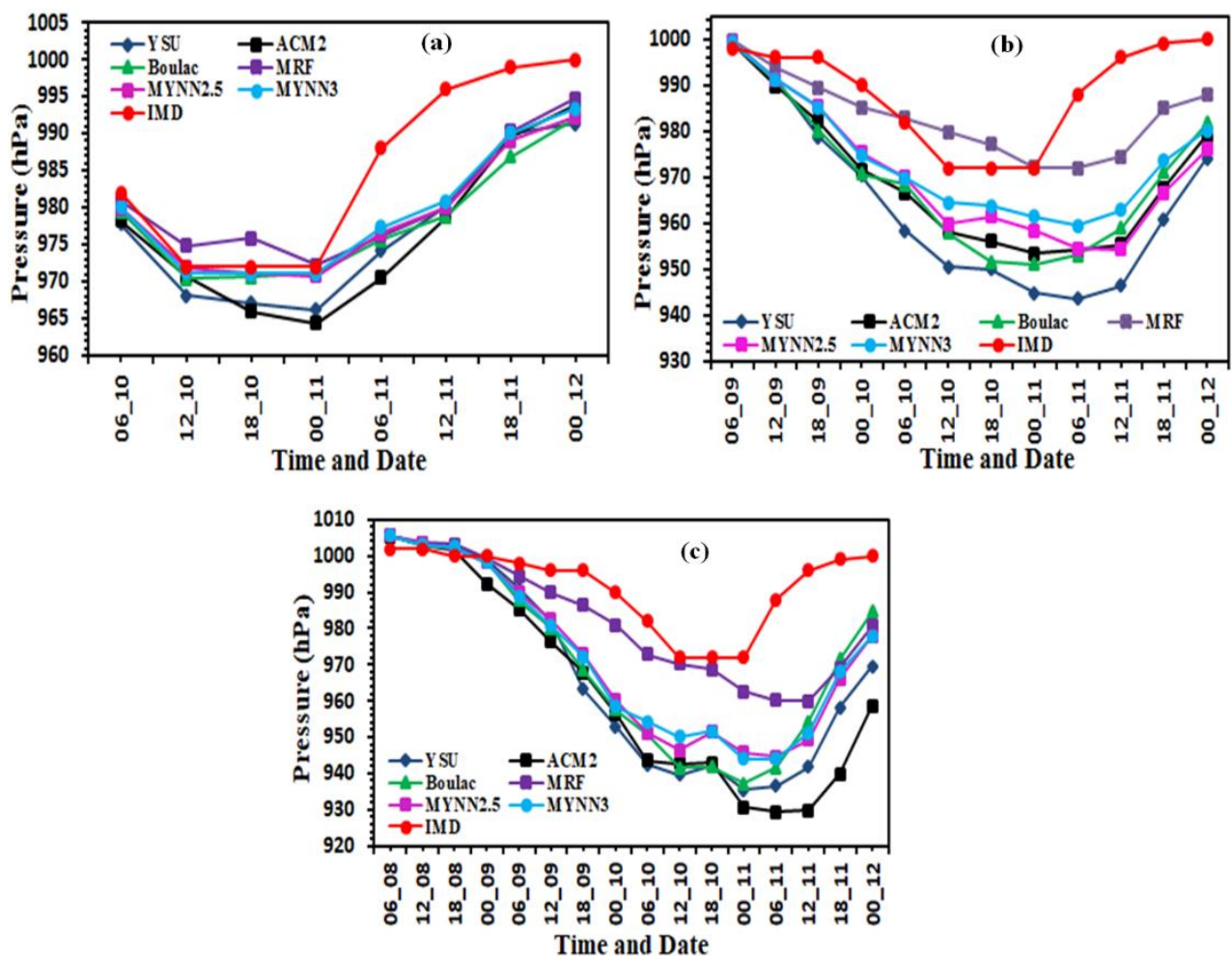

Fig. 3. The time evolution of pressure (hPa) for (a) $48 \mathrm{~h}$ during 0000 UTC of 10-12 October 2018, (b) $72 \mathrm{~h}$ during 0000 UTC of 09-12 October 2018, and (c) $96 \mathrm{~h}$ during 0000 UTC of 08-12 October 2018 with six different PBL schemes.

Table 6. RMSE and CC of minimum central pressure.

\begin{tabular}{lllllll|}
\hline \multirow{2}{*}{ PBL Schemes } & $48 \mathrm{~h}$ & \multicolumn{3}{c}{$72 \mathrm{~h}$} & $96 \mathrm{~h}$ & \\
\cline { 2 - 7 } & RMSE & $\mathrm{CC}$ & RMSE & $\mathrm{CC}$ & RMSE & $\mathrm{CC}$ \\
\hline YSU & 9.28 & 0.94 & 28.15 & 0.62 & 31.32 & 0.766 \\
ACM2 & 10.26 & 0.88 & 22.03 & 0.65 & 35.78 & 0.66 \\
Boulac & 9.14 & 0.90 & 21.60 & 0.72 & 26.37 & 0.85 \\
MRF & 8.09 & 0.83 & 10.14 & 0.60 & 15.38 & 0.66 \\
MYNN2.5 & 8.27 & 0.91 & 21.27 & 0.55 & 25.04 & 0.78 \\
MYNN3 & 7.69 & 0.92 & 17.62 & 0.64 & 24.66 & 0.78 \\
\hline
\end{tabular}

\subsection{Maximum sustained wind speed (MSWS) at the surface $(10 \mathrm{~m})$}

Any TC intensity is mainly measured in maximum sustained wind speed (MSWS) and minimum central pressure (MCP). In this study, MSWS is simulated at $10 \mathrm{~m}$ above sea level using six different PBL parameterization schemes with a fixed microphysics scheme and a cumulus physics scheme. Fig. 4 (a-c) shows that the time variation of MSWS for these six PBL schemes simulated values and IMD estimated values. From these figures, it 
is clear that MRF scheme underestimated MSWS for every simulation, and YSU overestimated in $72 \mathrm{~h}$ and $96 \mathrm{~h}$ simulations. According to Fig. 4(b-c), Boulac, MYNN2.5, and MYNN3 schemes predicted MSWS before the landfall is consistent with IMD observed values and after the landfall of the system, every scheme overestimated MSWS. In Fig. 4(a), every scheme's predicted MSWS are underestimated with IMD observed values.
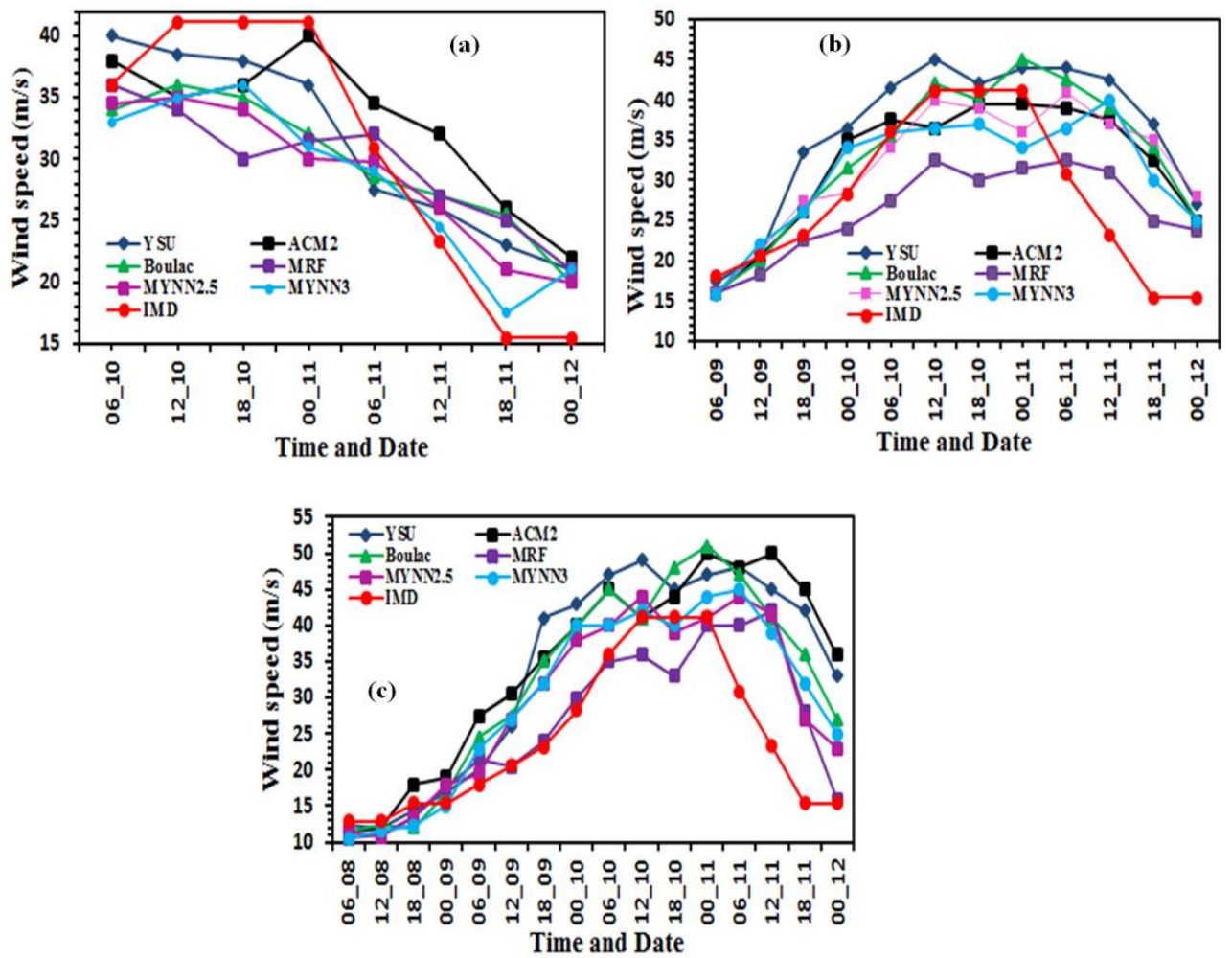

Fig. 4. The time evolution of wind speed $(\mathrm{m} / \mathrm{s})$ for (a) $48 \mathrm{~h}$ during $0000 \mathrm{UTC}$ of 10-12 October 2018, (b) $72 \mathrm{~h}$ during 0000 UTC of 09-12 October 2018, and (c) $96 \mathrm{~h}$ during 0000 UTC of 08-12 October 2018 with six different PBL schemes.

Table 7. RMSE and CC of maximum sustained wind speed at the surface $(10 \mathrm{~m})$.

\begin{tabular}{lllllll}
\hline PBL & $48 \mathrm{~h}$ & & $72 \mathrm{~h}$ & & $96 \mathrm{~h}$ & \\
\cline { 2 - 7 } Schemes & RMSE & CC & RMSE & CC & RMSE & CC \\
\hline YSU & 4.56 & 0.94 & 9.52 & 0.72 & 12.71 & 0.79 \\
ACM2 & 6.27 & 0.91 & 5.13 & 0.73 & 13.63 & 0.71 \\
Boulac & 6.06 & 0.93 & 5.99 & 0.74 & 10.43 & 0.86 \\
MRF & 7.13 & 0.84 & 4.29 & 0.70 & 6.72 & 0.80 \\
MYNN2.5 & 5.88 & 0.94 & 6.20 & 0.63 & 7.74 & 0.86 \\
MYNN3 & 5.21 & 0.96 & 5.23 & 0.66 & 8.44 & 0.84 \\
\hline
\end{tabular}


For $72 \mathrm{~h}$ simulation (Fig. 4(b)), it is found that YSU and Boulac schemes predicted MWS is $45 \mathrm{~ms}^{-1}$ which is overestimated by $4 \mathrm{~ms}^{-1}$ as compared to the IMD estimated MSWS (41 ms $\left.{ }^{-1}\right)$. Using MYNN2.5, MYNN3, and ACM2 schemes model simulated MWS are $41 \mathrm{~ms}^{-1}, 40 \mathrm{~ms}^{-1}$, and $39.5 \mathrm{~ms}^{-1}$, respectively, which are very close to IMD estimated value. In $96 \mathrm{~h}$ simulation, YSU, ACM2, Boulac, MYNN2.5, and MYNN3 schemes predicted MSWS at the time of maximum intensity are overestimated by $8,9,10$, 3 , and $4 \mathrm{~ms}^{-1}$, respectively. At the same time, the MRF scheme predicted MSWS is very less than IMD estimated MSWS for every simulation. Model simulated MSWS variation pattern with time for every PBL scheme used in this study is very similar to the IMD estimated pattern. At first, MSWS increases with time, and after attaining its maximum intensity, it decreases with time. After the landfall of the system (2300 UTC of $11^{\text {th }}-0000$ UTC of $12^{\text {th }}$ October), the storm MSWS is decreased rapidly for every PBL scheme because of lack of energy source, Land friction, and vegetation, etc. The RMSE and CC of Maximum Sustained Wind Speed at the surface $(10 \mathrm{~m})$ is shown in Table 7. The RMSE of MSWS is also low; it indicates that the model deviated less from the IMD observed value. The CC value also shows the good prediction of TC Titli simulation for 48 and $96 \mathrm{~h}$.

\subsection{Latent heat (LH) and moisture flux (MX)}

Latent heat (LH), Moisture flux (MX), and heat flux (HX) play a vital role in the development of TCs which are positively correlated with the intensification of TCs. The supply of Surface heat from LH is the fundamental energy source of TCs intensification. From the energy perspective, the cyclonic storm manures latent energy from the ocean via latent heat flux and increases potential energy by releasing latent energy in convective clouds. A part of heat release acts to increase the kinetic energy. Latent heat, which is concentrated around the center of circulation, drives the secondary circulation, increases low-level moisture convergence, and intensifies the primary circulation. 

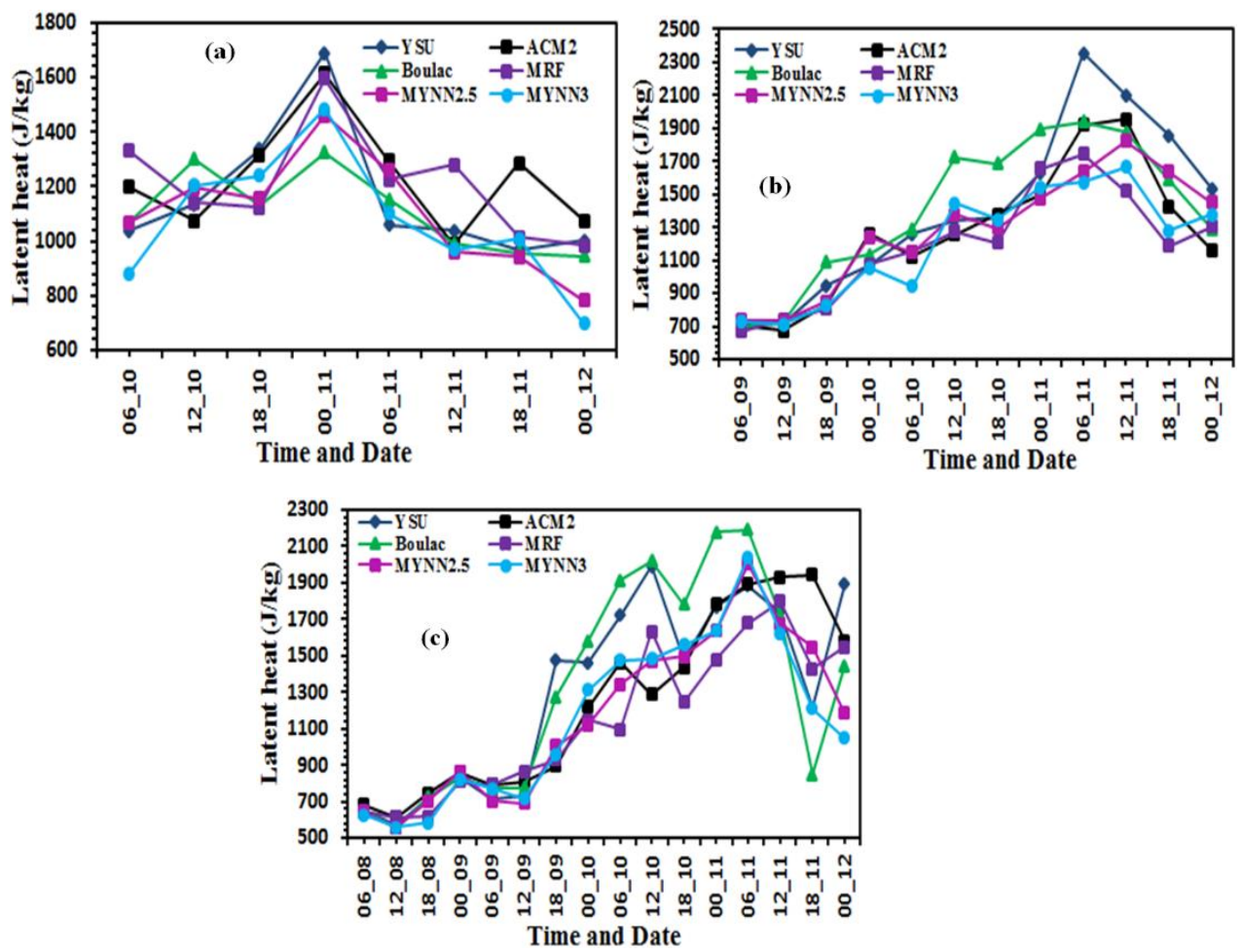

Fig. 5. The time evolution of latent heat (J/kg) for (a) $48 \mathrm{~h}$ during 0000 UTC of 10-12 October 2018, (b) $72 \mathrm{~h}$ during 0000 UTC of 09-12 October 2018, and (c) $96 \mathrm{~h}$ during 0000 UTC of 08-12 October 2018 with six different PBL schemes.

The time evolution of $\mathrm{LH}$ and $\mathrm{MX}$ during the TC 'Titli' intensification is presented in Fig. 5(a-c) and 6(a-c) for 48,72 and $96 \mathrm{~h}$ simulations which mainly shows how latent heat and moisture flux is related to the intensification of $\mathrm{TC}$ for six different PBL parameterizations schemes. From these figures, it is clear that both latent heat and moisture flux pattern is almost same over the time. The figure shows that latent heat and moisture flux are increased with time till the maximum intensity of $\mathrm{TC}$, and after the landfall (2300 UTC of 11th and 0000 UTC of 12th October) of the system, it is decreased with time which is very similar to MSWS. From these six schemes, YSU scheme holds the maximum value of latent heat and moisture flux. Time variation of LH is very similar to MSWS, as it is increased before the landfall and decreased after the landfall of the system. 

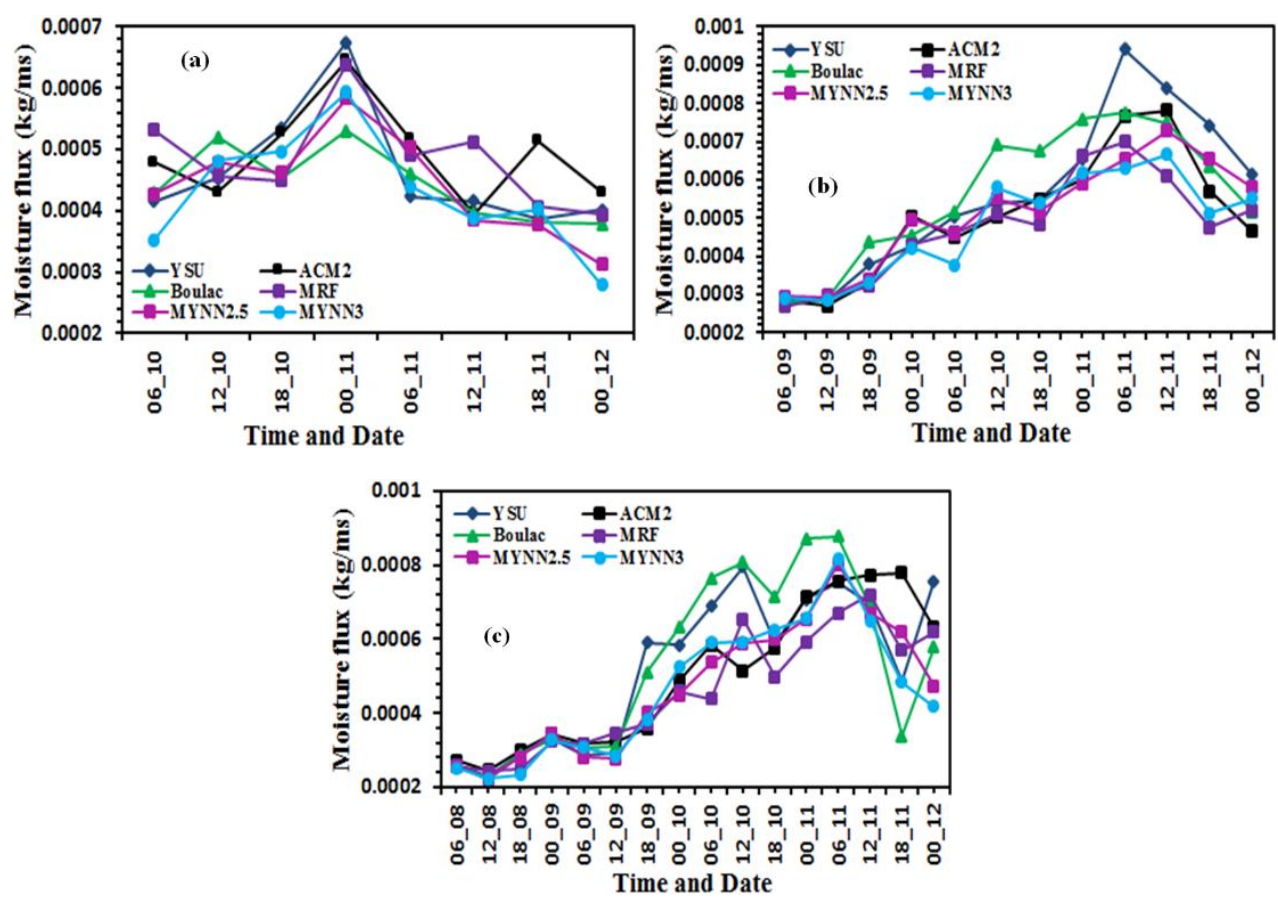

Fig. 6. The time evolution of moisture flux (kg/ms) for (a) $48 \mathrm{~h}$ during 0000 UTC of 10-12 October 2018, (b) $72 \mathrm{~h}$ during 0000 UTC of 09-12 October 2018 and (c) $96 \mathrm{~h}$ during 0000 UTC of 08-12 October 2018 with six different PBL schemes.

\subsection{Heat flux (HX)}

The energy source during TCs genesis is mainly heat flux which plays an important role in the intensification stage. The time variation of model-simulated area-averaged HX $\left(\mathrm{Wm}^{-2}\right)$ at the surface is presented in Fig. 7(a-c) using six different PBL schemes for 48, 72 , and $96 \mathrm{~h}$ simulations. Variation of HX is very close to variation of latent heat and MSWS. When the evaporation occurs between the air-sea boundaries, some energies transfer towards the upward direction as latent heat, and thus water vapor increases in the air. For atmospheric circulation, it acts as a key energy source. The maximum simulated heat flux is found for the YSU scheme, which is about $661 \mathrm{Wm}^{-2}$ for $72 \mathrm{~h}$ simulation, 516 $\mathrm{Wm}^{-2}$ for $48 \mathrm{~h}$ simulation, and $409 \mathrm{Wm}^{-2}$ for $96 \mathrm{~h}$ simulation. 

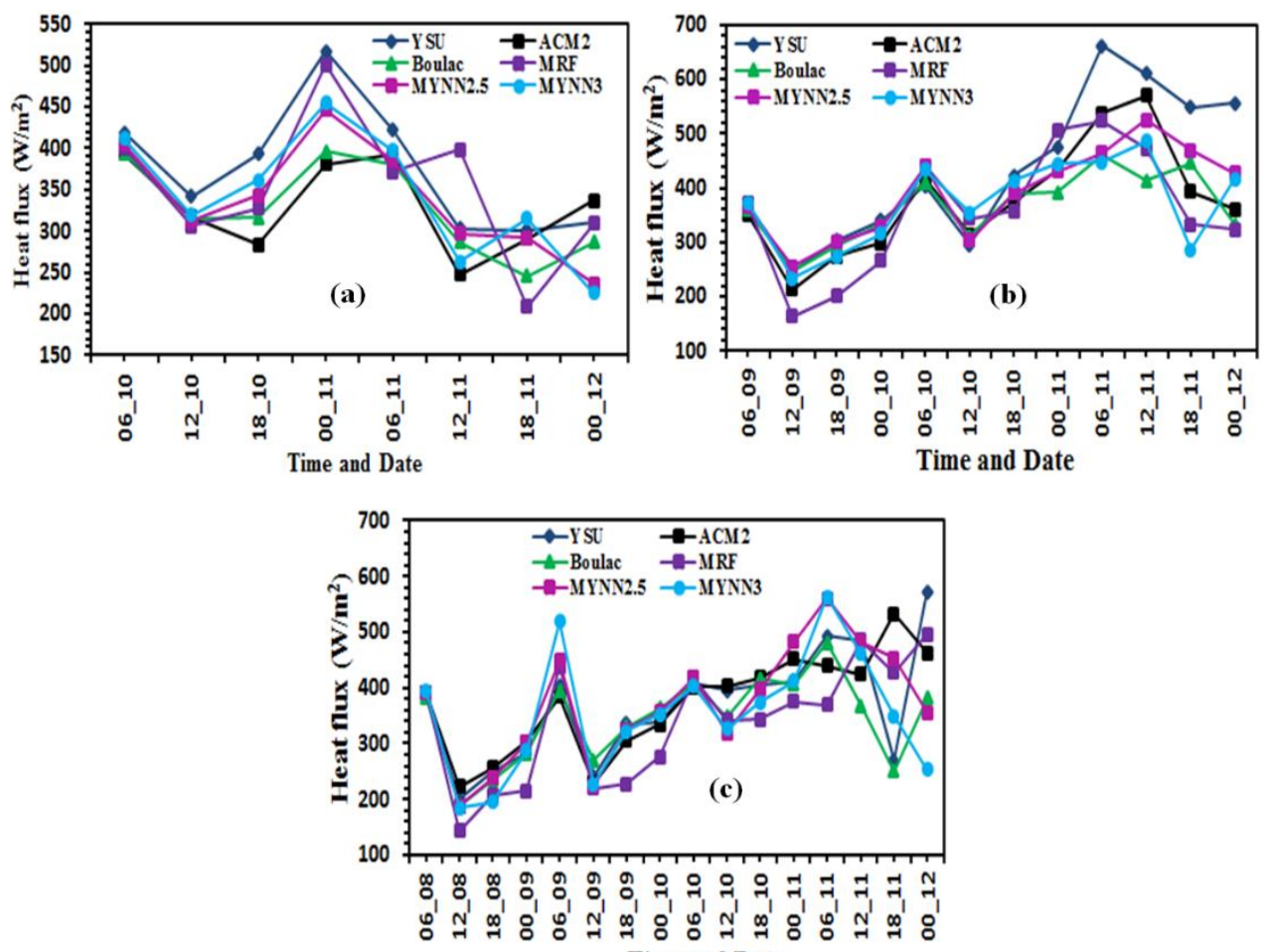

Time and Date

Fig. 7. The time evolution of heat flux $\left(\mathrm{W} / \mathrm{m}^{2}\right)$ for (a) $48 \mathrm{~h}$ during $0000 \mathrm{UTC}$ of $10-12$ October 2018, (b) $72 \mathrm{~h}$ during 0000 UTC of 09-12 October 2018, and (c) $96 \mathrm{~h}$ during 0000 UTC of 08-12 October 2018 with six different PBL schemes.

\section{Conclusion}

The TC 'Titli' has been selected to analyze the sensitivity of various PBL parameterization schemes on predicting the track pattern, intensity in terms of MCP and MSWS, latent heat, moisture flux, and heat flux. According to this study, the following conclusion can be made:

- The average track error for the overall three different simulations is minimum for Boulac and MYNN2.5 schemes. The landfall position error is also minimum for Boulac $(138 \mathrm{~km})$ and MYNN2.5 $(127 \mathrm{~km})$ in $96 \mathrm{~h}$ simulation, with landfall time is delayed by 3 and $6 \mathrm{~h}$, respectively. In $96 \mathrm{~h}$ simulation, ACM2 and MRF schemes show maximum average track error and landfall position error.

- The evolution patterns of MCP and MSWS are very similar to IMD observed pattern, but YSU and ACM2 schemes overestimated cyclone intensity for every simulation. On the other hand, MRF scheme underestimated the intensity in terms of MSWS. Before the landfall of the system Boulac, MYNN2.5, and MYNN3 schemes predicted MCP and MSWS are close to IMD observed MCP and MSWS. 
- All schemes simulate a significant amount of Latent heat, Moisture flux, and heat flux correlated with cyclone intensification.

Overall it can be specified that the Boulac, MYNN2.5, and MYNN3 schemes simulate the better intensity and track of TC 'Titli'.

\section{Acknowledgment}

The authors are grateful to the Department of Physics, Khulna University of Engineering \& Technology (KUET), for providing laboratory facilities in an atmospheric physics laboratory. The authors gratefully acknowledge the NCEP/NCAR for providing WRFARW modeling system and their reanalysis data sets. The authors are also thankful to India Meteorological Department (IMD) for providing the required observed meteorological data.

\section{References}

1. M. Alimohammadi and H. Malakooti, J. Earth Syst. Sci. 127, 41 (2018). https://doi.org/10.1007/s12040-018-0941-4

2. D. V. B. Rao, Mausam. 70, 195 (2019).

3. W. M. Gray, Monthly Weather Rev. 96, 669 (1968). https://doi.org/10.1175/1520-0493(1968)096<0669:GVOTOO>2.0.CO;2

4. R. D. Kanase and P. S. Salvekar, Meteorol. Atmos. Phys. 127, 537 (2015). https://doi.org/10.1007/s00703-015-0381-5

5. L. Chutia, B. Pathak, A. Parottil, and P. K. Bhuyan, Meteorol. Atmos. Phys. 131, 1483 (2019). https://link.springer.com/article/10.1007\%2Fs00703-018-0651-0

6. M. M. Alam, M. A. Hossain, and S. Shafee, Int. J. Climatol. 23, 1119 (2003). https://doi.org/10.1002/joc. 927

7. C. V. Srinivas, V. Yesubabu, R. Venkatesan, and S. S. V. S. Ramarkrishna, Meteorol. Atmos. Phys. 110, 19 (2010). https://doi.org/10.1007/s00703-010-0102-z

8. C. P. R. Sandeep, C. Krishnamoorthy, and C. Balaji, Curr. Sci. 115, 1143 (2018). https://doi.org/10.18520/cs/v115/i6/1143-1153

9. D. R. Pattanaik and Y. R. Rao, J. Earth Syst. Sci. 118, 309 (2009). https://doi.org/10.1007/s12040-009-0031-8

10. P. V. S. Raju, J. Potty, and U. C. Mohanty, Meteorol. Atmos. Phys. 113, 125 (2011). https://doi.org/10.1007/s00703-011-0151-y

11. M. S. Deshpande, S. Pattnaik, and P. S. Salvekar, Annales Geophysicae 30, 775 (2012). https://doi.org/10.5194/angeo-30-775-2012

12. S. Pattanayak, U. C. Mohanty, and K. K. Osuri, Sci. World J. 2012, 1 (2012). https://doi.org/10.1100/2012/671437

13. S. Mohandas and R. Ashrit, Natural Hazards 73, 213 (2014). https://doi.org/10.1007/s11069-013-0824-6

14. C. V. Srinivas, R. D. V. Bhaskar, V. Yesubabu, R. Baskaran, and B. Venkatraman, Quarterly J. Royal Meteorol. Soc. 139, 1810 (2013). https://doi.org/10.1002/qj.2064

15. K. S. Singh, B. Tyagi, V. K. Verma, and S. Maity, Meteorol. Appl. 26, 597 (2019). https://doi.org/10.1002/met.1787

16. K. K. Osuri, U. C. Mohanty, A. Routray, M. A. Kulkarni, and M. Mohapatra, Natural Hazards 63, 1337 (2012). https://doi.org/10.1007/s11069-011-9862-0

17. R. D. Kanase and P. S. Salvekar, Asia-Pacific J. Atmos. Sci. 51, 205 (2015). https://doi.org/10.1007/s13143-015-0071-8 
18. K. S. Singh and P. K. Bhaskaran, J. Atmos. Solar-Terrestrial Phys. 165, 10 (2017). https://doi.org/10.1016/j.jastp.2017.11.004

19. S. Kanada, A. Wada, M. Nakano, and T. Kato, J. Geophys. Res. 117, 1 (2012). https://doi.org/10.1029/2011JD016582

20. J. R. Rajeswari, C. V. Srinivas, P. R. Mohan, and B. Venkatraman, Pure Appl. Geophys. 177, 5523 (2020). https://doi.org/10.1007/s00024-020-02572-3

21. S. Y. Hong, Y. Noh, and J. Dudhia, Monthly Weather Rev. 134, 2318 (2006). https://doi.org/10.1175/MWR3199.1

22. J. E. Pleim, J. Appl. Meteorol. Climatol. 46, 1383 (2007). https://doi.org/10.1175/JAM2539.1

23. P. Bougeault and P. Lacarrere, Monthly Weather Rev. 117, 1872 (1989). https://doi.org/10.1175/1520-0493(1989)117<1872:POOITI>2.0.CO;2

24. S. Y. Hong and H. L. Pan, Monthly Weather Rev. 124, 2322 (1996). https://doi.org/10.1175/1520-0493(1996)124<2322:NBLVDI>2.0.CO;2

25. M. Nakanishi and H. Niino, Boundary-Layer Meteorol. 119, 397 (2006). https://doi.org/10.1007/s10546-005-9030-8

26. M. Nakanishi and H. Niino, J. Meteorol. Soc. Japan 87, 895 (2009). https://doi.org/10.2151/jmsj.87.895

27. J. B. Olson, J. S. Kenyon, W. Angevine, J. M. Brown, M. Pagowski, and K. Sušelj, NOAA (Technical Memorandum OAR GSD-61, 2019). https://repository.library.noaa.gov/view/noaa/19837

28. K. S. S. Lim and S. Y. Hong, Monthly Weather Rev. 138, 1587 (2010). https://doi.org/10.1175/2009MWR2968.1

29. J. S. Kain and J. M. Fritsch, J. Atmos. Sci. 47, 2784 (1990). https://doi.org/10.1175/1520-0469(1990)047<2784:AODEPM>2.0.CO;2

30. J. S. Kain and J. M. Fritsch, American Meteorological Society (Boston, MA, 1993) pp. 165. http://www.atmo.arizona.edu/students/courselinks/spring08/atmo336s1/courses/spring12/atmo 558/Lectures/kainmonogph.pdf

31. J. S. Kain, J. Appl. Meteorol. 43, 170 (2004). https://doi.org/10.1175/1520-0450(2004)043<0170:TKCPAU>2.0.CO;2

32. Very Severe Cyclonic Storm "Titli” Over Eastcentral Bay of Bengal (08-13 October 2018): Summary, Regional Specialised Meteorological Centre-Tropical Cyclones (New Delhi, India Meteorological Department, 2018). http://www.rsmcnewdelhi.imd.gov.in/images/pdf/publications/preliminary-report/titli.pdf

33. W. C. Skamarock, J. B. Klemp, J. Dudhia, D. O. Gill, D. M. Barker, W. Wang, and J. G. Powers, A Description of the Advanced Research WRF version 3, NCAR Technical note-475+ STR. (2008). http://dx.doi.org/10.5065/D68S4MVH

34. ARW Version 3.8.1; Modeling Systems User Guide, January (2017). http://www2.mmm.ucar.edu/wrf/users/docs/user_guide_V3.8/ARWUsersGuideV3.8.pdf

35. J. Dudhia, J. Atmos. Sci. 46, 3077 (1989). https://doi.org/10.1175/1520-0469(1989)046<3077:NSOCOD>2.0.CO;2

36. E. J. Mlawer, S. J. Taubman, P. D. Brown, M. J. Iacono, and S. A. Clough, J. Geophys. Res. 102, 16663 (1997). https://doi.org/10.1029/97JD00237

37. A. H. El-Shafie, A. El-Shafie, H. G. El Mazoghi, A. Shehata, and M. R. Taha, Int. J. Phys. Sci. 6, 1306 (2011). https://doi.org/10.4236/ns.2014.610069

38. A. L. Kondowe, Nat. Sci. 6, 691 (2014). https://doi.org/10.4236/ns.2014.610069

39. B. K. Mahala, P. K. Mohanty, and B. K. Nayak, Procedia Eng. 116, 655 (2015). https://doi.org/10.1016/j.proeng.2015.08.342 